\title{
PERANCANGAN INVERTER SATU FASA SEBAGAI PENGGERAK MOTOR INDUKSI SATU FASA
}

\author{
Agus Wiranto ${ }^{1)}$, Faraida Nafiri, ST., M.S ${ }^{2)}$, Syaiful Bakhri, ST. M. Eng. Sc. Phd ${ }^{3)}$ \\ 1) Mahasiswa S1 Jurusan Teknik Elektro Universitas Pamulang \\ 2 Dosen Jurusan Teknik Elektro Universitas Pamulang \\ ${ }^{3}$ Kaprodi Teknik Elektro Universitas Pamulang. \\ Jl Raya Puspitek No 11 Buaran, Tangerang Selatan, 15310 INDONESIA \\ Telp.: (021) 7412466 \\ E-mail : awiranto399@gmail.com 1
}

\begin{abstract}
PERENCANAAN INVERTER SATU FASA SEBAGAI PENGERAK MOTOR INDUKSI SATU FASA. Terjadinya pemadaman listrik dilakukan di daerah - daerah yang kurang pasokan energi listrik secara bergilir. Pemadaman listrik ini dilakukan karena kapasitas beban yang sudah melebihi kapasitas, Karena kebutuhan energi listrik yang dipergunakan untuk mengaliri peralatan elektronik modern semakin meningkat. Namun energi listrik yang disalurkan oleh PLN sebagai penyedia energi di Indonesia kepada konsumen tidak selamanya berjalan dengan baik, sewaktu - waktu bisa padam. Maka perlu diupayakan rekayasa alat-alat elektronik yang dapat menghemat energy listrik. Ada beberapa cara yang dapat dilakukan untuk mengurangi dalam mengendalikan penggunaan energi listrik yaitu dengan cara memasang atau menggunakan inventer yang dapat dilakukan sebagai pengendali kecepatan putar motor induksi di antaranya dengan kendali tegangan dan frekuensi yang dikenal dengan kendali V/f konstan. Kendali V/f konstan adalah salah satu cara untuk mengendalikan kecepatan putar motor induksi dengan merubah tegangan dan frekuensi, dengan cara menjaga konstan rasio keduanya. Hal yang sering dan umum dalam penerapan cara ini adalah dengan menggunakan perangkat yang dikenal sebagai inverter. Oleh karena itu pada penelitian ini penulis merancang inverter, khususnya inverter satu fasa dengan kendali V/f konstan, yang diaplikasikan untuk mengendalikan kecepatan putar motor di dunia induksi.
\end{abstract}

Kata Kunci : Inverter, Satu fasa, Induksi, Frekuensi,

\begin{abstract}
SINLE PHASE INVERTER AS SINGLE PHASE INDUCTION MOTOR DRIVER PLANNING. The power outage in region which lack of electricity supplay is done alternately. The power outage is done because of overload capacity, this is happened because the demand of electricity which used for activating modern electric equipment was increasing. But the electricity from the PLN as energy supplier in Indonseia not always on good condition, sometimes the power is gone. So we need to do some engineering on the equipment to save the electricity. There are some ways to decreasing and controlling the energy use by appliying an inverter to controlling the induction motor driver which controlling the voltage and frequency known ad constant V/f controller. Constant V/f controller is one of the ways to controlling the induction motor rotating speed by changing the voltage and frequency and keeping the constant ratio between them. The common way in applying this wayis buy using a device known as inverter. So in this research the writer is designing an inverter, especially in single phase inverter with constant V/f controller which can be applied for controlling the motor's rotating speed in induction world.
\end{abstract}

Keywords : inverter, single phase, induction, frequency. 


\section{PENDAHULUAN}

Dalam rangka penghematan dalam penggunaan Energi listrik perlu diupayakan rekayasa alat-alat elektronik yang dapat menghemat energy listrik. Ada beberapa cara yang dapat dilakukan untuk mengurangi dalam mengendalikan penggunaan energi listrik yaitu dengan cara memasang atau menggunakan inventer yang dapat dilakukan sebagai pengendali kecepatan putar motor induksi di antaranya dengan kendali tegangan dan frekuensi yang dikenal dengan kendali V/f konstan. Kendali V/f konstan adalah salah satu cara untuk mengendalikan kecepatan putar motor induksi dengan merubah tegangan dan frekuensi, dengan cara menjaga konstan rasio keduanya dalam rangka meningkatkan kemampuan sumberdaya manusia yang berkualitas dan profesional yang baik. Penulis akan membahas tentang bagaimana proses pekerjaanpenghematan penggunaan energi khususnya energi listrik, teknologi dan ilmu pengetahuan semakin berkembang dengan pesat termasuk ilmu pengetahuan di bidang elektro industri. Salah satu contohnya adalah penyearah dan buck konverter. Rectifier merupakan rangkaian yang berfungsi untuk menyearahkan tegangan AC ke tegangan DC sedangkan buck konverter merupakan rangkaian elektronika daya yang berfungsi menurunkan tegangan DC. Pada dasarnya rectifier dan buck konverter di industri memiliki peran yang sangat penting dimana buck converter dipakai untuk menurunkan tegangan jika supply dari PLN lebih besar dari input obyek yang dibutuhkan, sedangkan pada rumah tangga rectifier danbuck konverter banyak digunakan di peralatan rumah tangga seperti: AC (Air Conditioner), kulkas, kipas angin dll. Tetapi, Pada penelitian ini penulis mendesain buck konverter(inverter) sebagai penggerak motor induksi satu fasa.

Dalam bidang industri manufaktur motor banyak digunakan pada bagian produksi di pabrik. motor induksi merupakan motor yang paling umum sebagai peralatan pengerak diindustri. Cara pengoperasian motor induksi sangat sederhana, murah, mudah didapat, dan dapat langsung disambungkan ke sumber daya AC, namun dengan cara ini akan boros dalam penggunaan energi listrik.

Untuk penghematan penggunaan energi listrik salah satu penggunaan buck konverter yaitu untuk menggerakkan motor induksi satu fasa. Pada penelitian ini akan dibuat "Perancangan Inverter satu fasa sebagai Penggerak Motor Induksi satu fasa“. Sumber tegangan dari PLN 220V AC disearahkan oleh penyarah gelombang penuh yang menghasilkan tegangan output DC. Pada penyearah gelombang penuh tersebut dipasang sebuah filter $\mathrm{C}$ yang berfungsi untuk mengurangi ripple pada gelombang keluaran sehingga tegangan keluaran mendekati gelombang DC murni. Hasil keluaran rectifier masuk ke rangkaian buck konverter. Fungsi rangkaian buck konverter untuk menurunkan tegangan DC. Di mana pada rangkaian buck terdapat mosfet yang berfungsi untuk memutus dan menghubungkan dua tegangan yang penyulutannya menggunakan metode PWM. Hasil keluaran rangkaian buck konverter akan menjadi masukan bagi Inverter. Hasil secara keseluruhan yang diinginkan dari penelitian ini adalah keluaran tegangan rangkaian Inverter mempunyai $200 \mathrm{~V}$ AC dengan frekuensi $50 \mathrm{~Hz}$ yang bias di atur kecepatanya. Rangkaian Inverter digunakan untuk mengerakan motor induksi satu fasa $125 \mathrm{~W}$.

\section{METODOLOGI}

\section{Bahan dan Alat}

Untuk menunjang penelitian ini dibutuhkan komponen-komponen dan bahan yang dibutuhkan untuk gunakan dalam penelitian diantaranya :

\begin{tabular}{clc}
\multicolumn{3}{c}{ Tabel 1. Kebutuhan Komponen } \\
\hline No & Nama Komponen dan Nilai & Jumlah \\
\hline 1 & IC Regulator 7805 & 1 \\
2 & Dioda 4 kaki & 1 \\
3 & Elco C3A & 1 \\
4 & Cristal 8MHz & 1 \\
5 & IC ATMega16 & 1 \\
6 & Potensio B10k & 1 \\
7 & Resistor & 4 \\
8 & Optocopler & 4 \\
9 & Travo stepdown 1A & 1 \\
10 & Software Code Vision AVR & 1 \\
\hline
\end{tabular}

Selain bahan komponen -komponen diatas di butuhkan alat kerja berupa Solder, digital multitester, digital tang ampere dan lain sebagainya.

\section{Tata Kerja}

Blok diagram alur kerja sebuah inverter secara keseluruhan dari sistem ditunjukkan pada Gambar 1. dimana PLN mensuplai penyearah (rectifier) kemudian tegangan keluaran penyearah masuk ke dalam buck konverter setelah itu hasil dari buck konverter dikendalikan melalui mikrokontroller dan hasilnya masuk ke inverter 


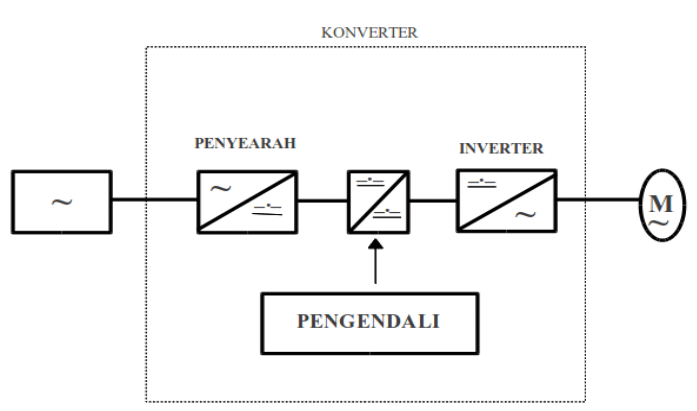

Gambar 1. Blok Diagram System

Dalam penelitian ini desain perangkat lunak yang digunakan adalah mikrokontroller ATMega16. Perancangan mikrokontroller ini digunakan sebagai kontrol PWM(Pulse Witdh Modulation) dari buck konverter, boost konverter, dan inverter dengan memanfaatkan frekuensi switching yang sesuai dengan performance dari ATMega16. Mikrokontroller ini nanti akan terhubung pada potensio yang digunakan sebagai kontrol PWM(Pulse Witdh Modulation) pada modul Inverter ini. Untuk mengetahui semua sistem yang telah dirancang sesuai dengan hasil yang diharapkan dalam penelitian, dilakukan penghubungan terhadap masing-masing perangkat. Secara detail tahaptahapan pengerjaan penelitian ini terlihat Flowchart pada Gambar No.2 berikut ini :

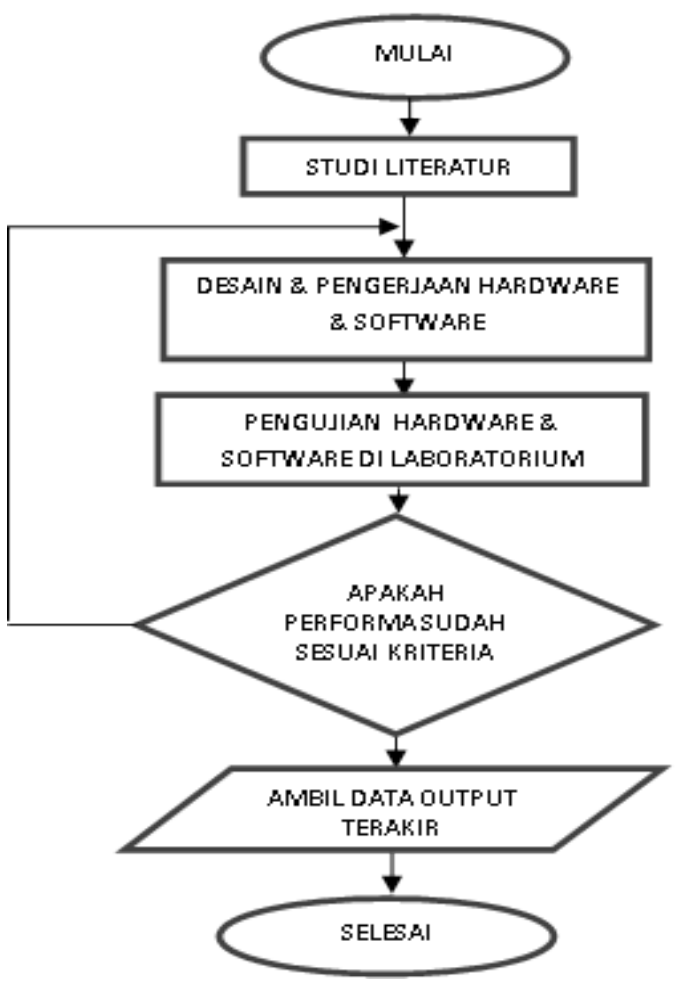

Gambar 2. Flowchart tahap-tahap pengerjaan
Inverter merupakan suatu rangkaian penyaklaran elektronik yang dapat mengubah sumber tegangan arus searah $(D C)$ menjadi tegangan arus bolak-balik $(A C)$ dengan besar tegangan dan frekuensi yang dapat di atur. Tegangan bolak-balik yang dihasilkannya berbentuk gelombang persegi dan pada pemakaian tertentu diperlukan filter untuk menghasilkan bentuk gelombang sinusoida. Pengaturan besar tegangan dapat dilakukan dengan 2 cara. Pertama, dengan mengatur tegangan input $D C$ dari luar tetapi lebar waktu penyaklaran tetap. Kedua, mengatur lebar waktu kerja dengan tegangan input $D C$ tetap. Pada cara yang kedua besar tegangan $A C$ efektif yang dihasilkan merupakan fungsi dari pengaturan lebar pulsa waktu kerja. Cara inilah yang disebut dengan PWM (Pulse Width Modulation), Perancangan dasar dari IGBT(Insulated Gate Bipolar Transistor) hampir sama dengan Regulator kecuali adanya penambahan layer $\mathrm{P}+$ pada colector diatas layer drain $\mathrm{N}+$ dari MOSFET. Komponen ini memiliki impedansi input yang tinggi dari MOSFET, tetapi karakteristik konduksi seperti BJT. Jika gate adalah positif dengan respect ke emitter , sebuah N-chanel diinduksikan pada daerah P. Ini di forward-biaskan pada base emitter junction dari PN-P transistor., menjadikan on dan menyebabkan modulasi konduktivitas pada daerah N-, memberikan reduksi signitifikan pada drop over konduksi pada MOSFET itu. Strukutur IGBT(Insulated Gate Bipolar Transistor) dengan rangkaian ekuivalennya ditunjukkan Seperti tergambar di Gambar No 3 dibawah ini.

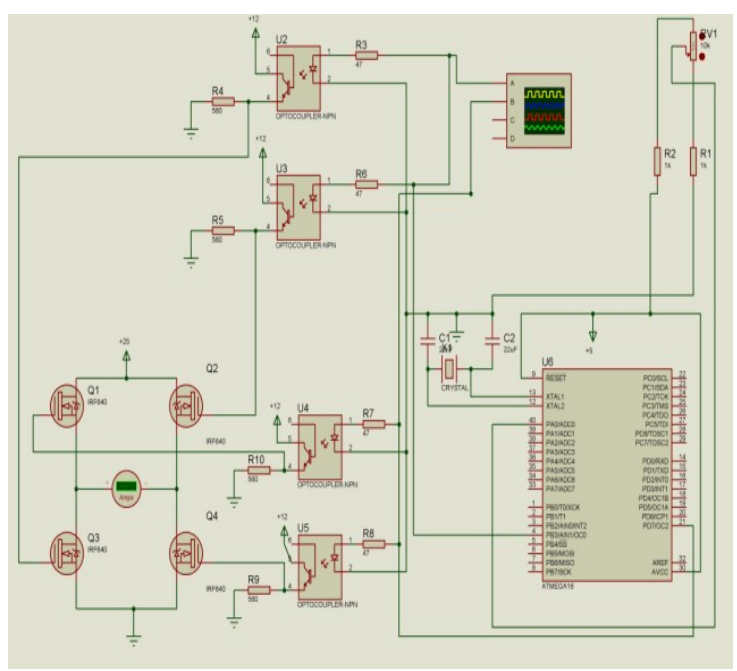

Gambar 3. Perancangan IGBT dalam sistem PWM

Dalam penggunaan mikrokontroller AVR menggunakan software Code Vision AVR.. Mikrokontroller AVR mendukung sistem download secara ISP (In-System Programming), Seperti umumnya mikrokontroller, program untuk 
mikrokontroller AVR ditulis menggunakan bahasa assembly. Code Vision AVR merupakan softwareCcross compiler, dimana program dapat ditulis menggunakan bahasa-C. Dengan menggunakan pemrograman bahasa-C diharapkan waktu desain (deleloping time) akan menjadi lebih singkat. Setelah program dalam bahasa-C ditulis dan dilakukan kompilasi tidak terdapat kesalahan (error) maka proses download dapat dilakukan. Seperti yang terlihat pada Gambar 4

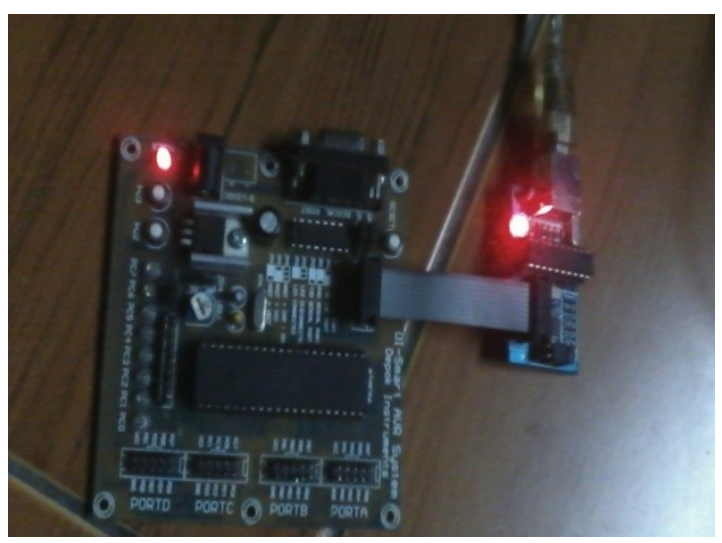

Gambar 4. Proses Instalasi Software ke Hardwere

\section{HASIL DAN PEMBAHASAN}

Inverter merupakan suatu rangkaian penyaklaran elektronik yang dapat mengubah sumber tegangan arus searah (DC) menjadi tegangan arus bolak-balik (AC) dengan besar tegangan dan frekuensi yang dapat di atur. Tegangan bolak-balik yang dihasilkannya berbentuk gelombang persegi dan pada pemakaian tertentu diperlukan filter untuk menghasilkan bentuk gelombang sinusoida. Pengaturan besar tegangan dapat dilakukan dengan 2 cara yaitu :

1. Dengan mengaturtegangan input DC dari luar tetapi lebar waktu penyaklaran tetap. Kedua, mengatur lebar waktu penyaklaran dengan tegangan input DC tetap.

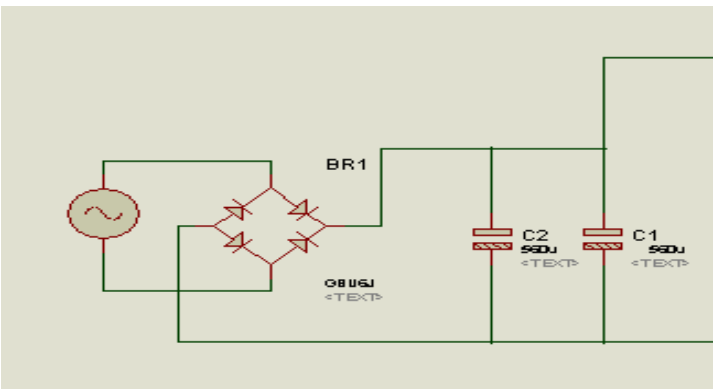

Gambar 5. Rangkaian Penyearah satu fasa
2. Pada cara yang kedua besar tegangan AC efektif yang dihasilkan merupakan fungsi dari pengaturan lebar pulsa waktu kerja.

Cara yang tergambar diatas atau disebut dengan PWM (Pulse Width Modulation). Struktur inverter umumnya mempunyai bentuk seperti ditunjukkan pada Gambar 4. Inverter terdiri dari sebuah rangkaian utama yang terbentuk dari rangkaian penyearah/rectifier yang dikontrol atau tidak (yang mengubah arus bolak-balik (AC) menjadi arus searah (DC) dan menghilangkan riak (ripple) yang terdapat pada arus searah), sebuah rangkaian inverter (yang mengubah arus searah (DC) menjadi arus bolak-balik (AC) dengan frekuensi beragam) dan sebuah rangkaian kontrol/rangkaian pengaturan penyalaan yang digunakan untuk mengatur tegangan dan frekuensi yang dihasilkan inverter.

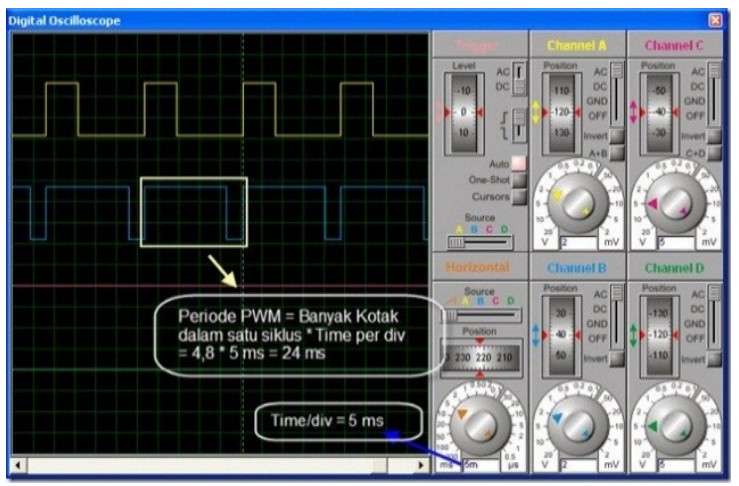

Gambar 6. Output gelombang buck dilihat menggunakan tampilan Proteus

Apabila diberi tegangan dari sumber $A C$ sebesar 220 v sehingga didapatkan tegangan $D C$ sebesar $198 \mathrm{v}$ dan kemudian di filter dengan menggunakan kapasitor sehingga menghasilkan tegangan $308 \mathrm{v}$. berikut ini perhitungan dari rectifier :

$$
\begin{aligned}
& V_{o}=0,636 * V_{m} \\
& =0,636 * 311 \\
& =198 \mathrm{~V}
\end{aligned}
$$

Jika disetting Ripple Factor $<1 \%$ dengan menggunakan beban motor induksi satu fasa yang memiliki daya $125 \mathrm{~W}$ 0,5A maka kapasitornya bernilai :

$$
\mathrm{R}=\frac{V^{2}}{W}=\frac{220^{2}}{400}=121 \mathrm{ohm}
$$




$$
\begin{aligned}
\mathrm{C}= & \frac{1}{4 * f * r} *\left(\frac{1}{\sqrt{2 * R F}}+1\right) \\
& =\frac{1}{4 * 50 * 121} *( \\
\frac{1}{\sqrt{2 * 0,01}} & +1) \\
& =\frac{1}{24200} *(71,42+1)=
\end{aligned}
$$

$299,2 \mathrm{uF}$

Maka keluaran DC nya setelah lewat Filter C

$$
\begin{gathered}
V_{D C}=V_{n}=\frac{V_{i}}{4 f r C} \\
\frac{311}{4 * 50 * 121 * 4700 * 10^{-6}} \\
=311-\frac{311}{113,74} \\
=308 \mathrm{~V}
\end{gathered}
$$$$
=311
$$

Jika dengan Ripple Factor ( $R F$ ) 1\%, maka didapatkan nilai kapasitor sebesar 299,2 uF oleh karena itu dalam perencanaan dan pembuatan penyearah akan menggunakan Kapasitor $560 \mathrm{uF}$ sehingga didapatkan Ripple Factor ( $R F$ ) untuk beban motor induksi satu fasa $125 \mathrm{~W} 0,5 \mathrm{~A}$.

Mencari ripple factor :

$$
\begin{aligned}
\mathrm{RF} & =\frac{1}{\sqrt{2 *(4 * f * R * R * C-1)}} \\
& =\frac{4 * 50 * 4700 * 10^{-6}}{\sqrt{2(i \dot{i} 121-1)}} \\
\frac{1}{\dot{i}} & \frac{1}{\sqrt{2 * 112,74}} \\
& =0,006 \\
& =0,6 \%
\end{aligned}
$$

Pada waktu pengujian input dinaikan secara bertahap dengan nilai input awal 20V. Saat input $60 \mathrm{~V}$ motor berjalan sangat pelan setelah dinaikan secara bertahap maka motor berputar lebih cepat dan juga diperoleh efisiensi dayanya yang dapat dilihat pada Tabel Berikut.

\begin{tabular}{ccc}
\multicolumn{3}{c}{ Tabel 2. Efisiensi daya } \\
\hline P in ( W) & P Out ( W $)$ & Efisiensi ( \% ) \\
\hline 20.5 & 15.5 & 75.61 \\
17.5 & 12.5 & 71.43 \\
15.5 & 11. & 70.97 \\
11.5 & 9.5 & 82.61 \\
11 & 8.5 & 77.27 \\
10.5 & 6.5 & 61.9 \\
\hline
\end{tabular}

\section{Pengujian Filter Rc}

\begin{tabular}{ccccc} 
& \multicolumn{2}{c}{ Rangkaian $R_{C}$} & filter terdiri dari dua \\
kapasitor & $C_{1} \quad$ dan $\quad C_{2}$ & sebuah resistor.
\end{tabular} Prinsip kerja filter ini adalah membuat gelombang yang dihasilkan dari rectifier mendekati gelombang DC murni. Pada saat rectifier mengeluarkan gelombang tegangan pada nilai puncak, maka kapasitor $C_{1}$ akan terisi dengan muatan (charge). Ketika gelombang tegangan menurun, nilainya menuju titik nol, $C_{1}$ akan mengeluarkan muatan (discharge)

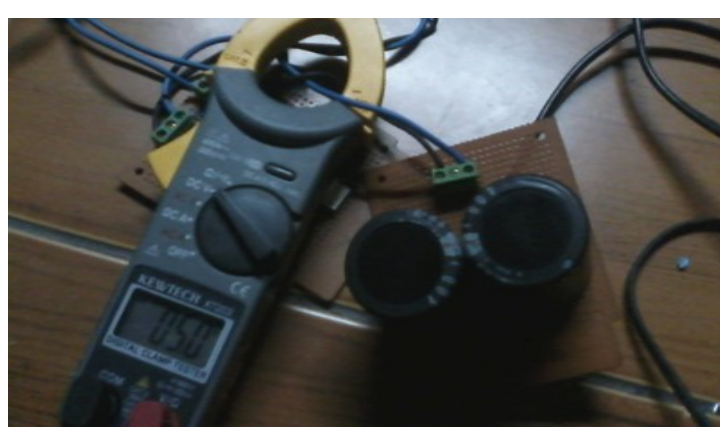

Gambar 4.5 Filter Kapasitor

Kondisi $C_{1}$ yang selalu terisi muatan dan mengeluarkannya membuat ripple gelombang semakin kecil, selanjutnya gelombang diperhalus oleh $C_{2}$ hingga gelombang tegangan keluaran menyerupai gelombang tegangan DC.Tegangan Rata - Rata (VDC)

$$
V_{c}=V_{M} \cdot e^{\frac{-t}{R C}}
$$


waktu pembuangan kapasitor adalah dari satu puncak mendekati puncak berikutnya, dimana tdis $\cong T$ ketika tegangan kapasitor mencapai nilai minimumnya.

$$
V_{C(M I N)}=V_{M} \cdot e^{\frac{-T}{R C}}
$$

Selama RC $>>\mathrm{T} . \quad \frac{T}{R C} \quad$ menjadi lebih kecil dari 1; $e^{\frac{-T}{R C}}$ mendekati 1 dan dapat dituliskan sebagai

$$
\begin{gathered}
e^{\frac{-T}{R C}}=1-\quad \frac{T}{R C} \quad \text { oleh karena itu } \\
V_{C(\text { MIN })}=V_{M}\left(1-\frac{T}{R C}\right)
\end{gathered}
$$

Tegangan ripple peak to peak adalah

$$
\begin{aligned}
& V_{r \cdot p-p}=V_{M}-V_{c(\text { Min })} \\
& V_{r \cdot p-p}=V_{M}-V_{M}+\frac{V_{M .} T}{R C} \\
& V_{r \cdot p-p}=\frac{V_{M .} T}{R C}
\end{aligned}
$$

Dengan frekuensi jala-jala adalah $50 \mathrm{~Hz}$, maka reppel penyearah gelombang penuh adalah $100 \mathrm{~Hz}$, Sehingga :

$$
\begin{aligned}
& V_{r . p-p}=\frac{V_{M \cdot} T}{R C}=\frac{V_{M .}}{R C f}= \\
& \frac{0,01 V_{M}}{R C}
\end{aligned}
$$

untuk memperoleh tegangan $D C$, tegangan maksimum dikurangi tegangan ripple peak to peak dibagi dua.

$$
V_{D C}=V_{M}-\frac{V_{r, p-p}}{2}
$$

$$
\begin{aligned}
& V_{D C}=V_{M}-\frac{0,01 V_{M}}{2 R C}= \\
& V_{M}\left(1-\frac{0,01 V}{R C}\right)
\end{aligned}
$$

Tegangan ripple puncak adalah :

$$
V_{r,(p)}=\frac{0,01 V_{M}}{2 R C}
$$

Pada perencanaan dan pembuatan rectifier dan filter C maka rectifier tersebut menggunakan sebuah dioda power empat kaki sedangkan pada filter $\mathrm{C}$ menggunakan dua kapasitor. Pada penggunaan Filter C yang mempergunakan dua buah kapasitor yang difungsikan untuk mengurangi ripple pada gelombang keluaran sehingga tegangan keluaran mendekati gelombang $D C$ murni. Untuk kapasitor motor 125W 0,5A didapatkan hasil pengukuran:

$\mathrm{Zu}=67 \Omega$

$\mathrm{Ru}=39 \Omega$

$\mathrm{Zp}=52 \Omega$

$\mathrm{Rp}=48 \Omega$

$\operatorname{Cos} \cdot \mathrm{Qu}=\frac{R u}{Z u}=\frac{39}{67}=0,5836$

$\mathrm{Qu}=35^{\circ} 42^{\prime}$

$\operatorname{Cos} . \mathrm{Qu}=\frac{R p}{Z p}=\frac{48}{52}=0,9231$

$\mathrm{Qp}=23^{\circ} 22^{\prime}$

$\mathrm{Q}=\mathrm{Qu}-\mathrm{Qp}$

$=35^{\circ} 42^{\prime}-23^{\circ} 22^{\prime}$

$=12^{\circ} 20^{\prime}$

$\mathrm{Qc}=90^{\circ}-12^{\circ} 20^{\prime}$

$=77^{\circ} 40^{\prime}$

$\mathrm{Tg} \cdot \mathrm{Qc}=77^{\circ} 40^{\prime}=4,5802$ 


$$
\begin{aligned}
C & =\frac{1}{314 \cdot x \cdot 48 \times 4,5802} \mathrm{~F} \\
& =\frac{1}{314 \cdot x \cdot 48 \times 4,5802} \mu \mathrm{F} \\
& =14,5 \mu \mathrm{F}
\end{aligned}
$$

\section{Pengujian PWM(Pulse Witdh Modulation)}

Rangkaian otocoupler pada Gambar 7 menggunakan IC 4N25 dan dihubungkan dengan transistor C 372. grond pada sisi masukan harus dipisahkan dengan grond pada sisi keluaran. Pemisahan grond terkait dengan sifat dasar dari otocoupler yang berfungsi mengisolasi rangkaian masukan dengan rangkaian keluaran.

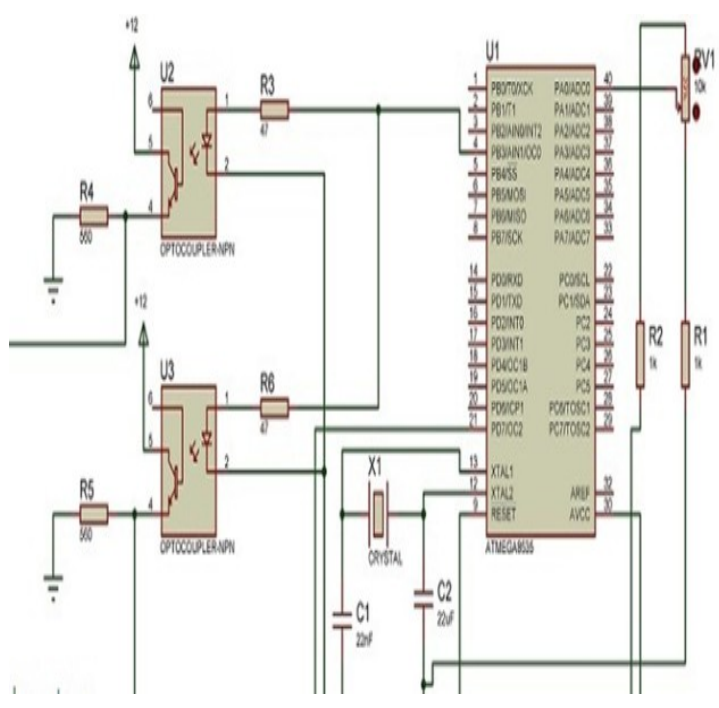

Gambar 7. Rangkaian Dasar pengujian PWM

Pada saat IGBT(Insulated Gate Bipolar Transistor) diberikan masukan sinyal dari rangkaian PWM(Pulse Witdh Modulation) yang dihasilkan osilator pembangkit gelombang pulse PWM dan rangkaian komparator, maka frekuensi keluaran juga sama dengan masukan yang membedakan adalah besar Amplitudo yaitu 12 volt. Perbedaan Amplitudo antara masukan dan keluaran karena keluaran dari rangkaian IC Regulator 7805 dihubungkan dengan transistor C 372 untuk dikuatkan. Tegangan masukan PWM berupa sinyal gelombang kotak dengan frekuensi $25 \mathrm{kHz}$. Maka tegangan keluaran pun harus berupa sinyal gelombang kotak pula. Keluaran PWM yang berupa sinyal gelombang kotak digunakan untuk mengaktifkan IGBT(Insulated Gate Bipolar Transistor).

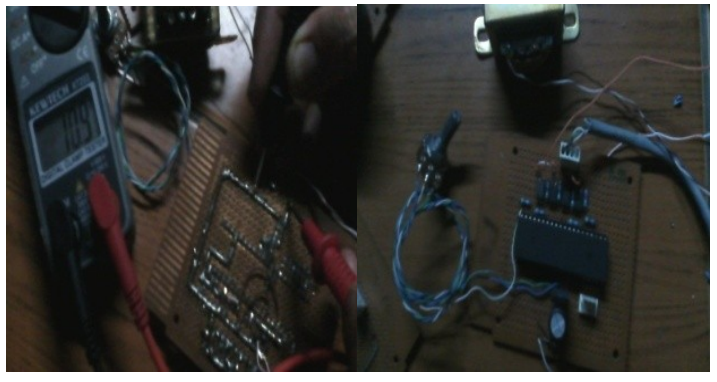

Gambar 8 Pengukuran Pengengali IGBT / PWM

Pengujian rangkaian PWM(Pulse Witdh Modulation) dilakukan pada pin kolektor transistor C 372 sebagai keluaran dari rangkaian PWM yang telah mengalami penguatan. Rangkaian PWM pada Gambar 7 di atas dengan hasil pembacaan pada Oscilloscope seperti Gambar No 9 dibawah ini:

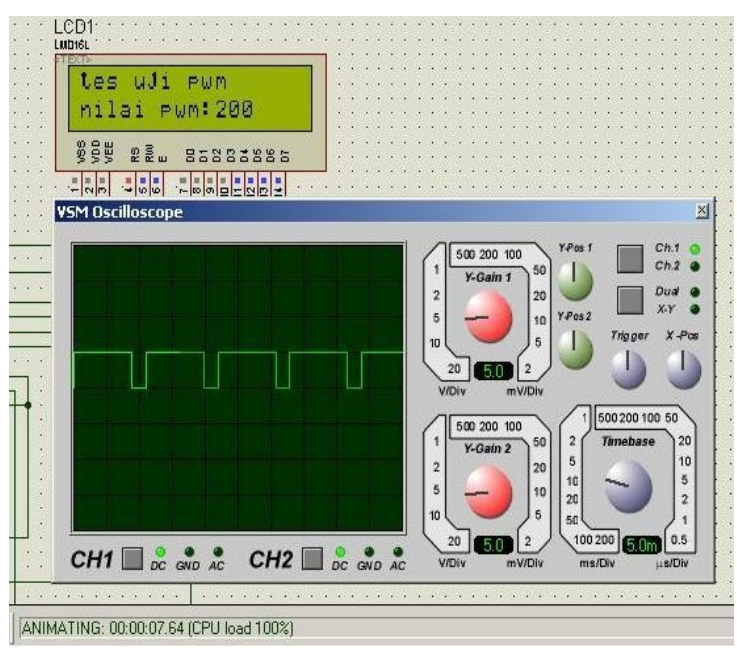

Gambar 9. Bentuk Pulse keluaran PWM

\section{KESIMPULAN}

Setelah dilakukan proses perencanaan, pembuatan dan pengujian alat serta dengan membandingkan dengan teori - teori penunjang, dan dari data yang telah didapat maka dapat disimpulkan dari inverter (Pengubah tegangan DC ke AC) satu fasa sinkron berbasis PWM(Pulse Witdh Modulation) Pada waktu pengujian input dinaikan secara bertahap dengan nilai input awal 20V. Saat input $60 \mathrm{~V}$ motor berjalan sangat pelan setelah dinaikan secara bertahap maka motor berputar lebih cepat dan juga diperoleh efisiensi dayanya yang dapat dilihat pada Tabel No.2 diatas. Sehingga putaran motor dapat dikendalikan melalui inverter.

\section{UCAPAN TERIMAKASIH}


Puji syukur Penulis ucapkan Kepada Allah SWT, karena atas berkat dan rahmat-Nya, Penulis dapat menyelesaikan laporan penelitian ini, Oleh karena itu Penulis mengucapkan terimakasih kepada :

1. Bapak Syaiful Bakhri, ST. M. Eng. Sc. Phd. Selaku Kaprodi Teknik Elektro Universitas Pamulang

2. Ibu Faraida Nafiri, ST., M.S. selaku dosen pembimbing.

3. Rekan-rekan Kerja, Orang tua Ibu Siti Komsiyah (Alm.), Bp Basuki (Alm), Istri Maemunah dan anakku Faaris Ash Shiddiiqy dan Faaris Al Ghifary .

4. Semua Pihak yang terlibat dan tidak penulis sebutkan satu persatu.

\section{REFERENSI}

[1] Electric Machines \& Power Electronics Laboratorty Department of Electrical Engineering, Texas A\&M University

[2] Helly Andri, Inverter satu fasa sinkron berbasis digital phasa locked loop. Penerbit Universitas Indonesia Juni 2012.

[3] Kamus Komponen Elektronika. Deni Arifianto. Kawan Pustaka Jakarta

[4] Mokh. Sholihun Hadi. Komunitas eLearning Ilmu Komputer.Com, IlmuKomputer.Com 2003-2008.

[5] Prinsip Dasar ElektroTeknik, Prof. Dr. Zuhal M. Sc. EE dan Ir Zhanggischan. PT Gramedia Pustaka Utama Jakarta 2004. 
